\title{
Neurocysticercosis and hippocampal damage: a causal link favored by epileptogenesis or neuroinflammation?
}

\author{
Oscar H. Del Brutto', Victor J. Del Brutto \\ ${ }^{1}$ School of Medicine, Universidad Espiritu Santo, Guayaquil 999165, Ecuador. \\ ${ }^{2}$ Department of Neurology, University of Chicago Medical Center, Chicago, IL 60637, USA.
}

Correspondence to: Dr. Oscar H. Del Brutto, School of Medicine, Universidad Espíritu Santo, Km 3, vía Puntilla-Samborondón, Samborondón, Guayaquil 999165, Ecuador. E-mail: oscardelbrutto@hotmail.com

How to cite this article: Del Brutto OH, Del Brutto VJ. Neurocysticercosis and hippocampal damage: a causal link favored by epileptogenesis or neuroinflammation? Neuroimmunol Neuroinflammation 2017;4:152-4.

\section{Article history: Received: 05-05-2017 Accepted: 10-05-2017 Published: 08-08-2017}

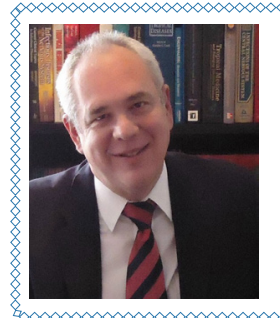

Dr. Oscar H. Del Brutto, is a Professor of Neurology, School of Medicine, Universidad Espíritu Santo, Ecuador, and the Director of the Atahualpa Project.

Cysticercosis is a frequent parasitic infection of the nervous system that occurs when humans become intermediate hosts of the pork tapeworm Taenia solium ( $T$. solium), after ingesting its eggs. The disease is usually transmitted person-to-person, from Taenia carriers to healthy individuals, through non-hygienic handling of food or by direct contact with human feces. Ingestion of undercooked pork contaminated with cysticerci as the cause of human cysticercosis is a common misconception, since the role of pigs is to maintain the infection cycle by causing human taeniasis..$^{[1]}$

While cysticerci may invade the subcutaneous tissue, striated muscles and many other organs, clinically relevant disease is often observed in patients with neurocysticercosis (NCC), defined as the infection of the central nervous system and its coverings by the encysted larval stage of $T$. solium. Most symptomatic NCC patients (up to $80 \%$ of cases) develop recurrent seizures (epilepsy), which is most often seen in patients with parasites located in the brain parenchyma. ${ }^{[2]}$ NCC is a major cause of secondary epilepsy in many developing countries and is currently considered the single most important disease explaining the higher number of epilepsy seen in these regions. ${ }^{[3]}$ In addition, travelling and immigration of people from endemic to non-endemic areas has caused increased prevalence 
rates of epilepsy secondary to NCC in developed countries of North America and Western Europe. ${ }^{[4]}$

For a better understanding of mechanisms involved in the pathogenesis of epilepsy secondary to NCC, a review of the stages of involution of parenchymal brain cysticerci is mandatory. After lodging in the brain parenchyma, cysticerci establish as vesicular (viable) cysts, which provoke little or no inflammatory changes in neighboring tissues. In most cases, vesicular cysts degenerate and are transformed into calcified nodules due to the attack of the host's immune system. Intermediate involutive stages during which cysticerci experience such degeneration have been called "colloidal" (cysticerci showing degenerative signs but still with liquid contents) and "granular" (compact lesions with more advanced degenerative changes) stages, respectively. ${ }^{[5]}$

Parenchymal brain cysticerci in any of the aforementioned stages may be associated with reactive seizures. Compressive effect on the brain parenchyma is the most likely explanation for seizures occurring in patients with vesicular cysts. Degenerating cysticerci may be associated with seizures due to the inflammatory reaction induced by the host's immune attack. In cases of calcified cysticerci, the gliosis that develops around dead parasites or the exposure of remaining parasitic antigens (trapped in the interior of calcifications) to the brain parenchyma could be the cause of recurrent seizures. ${ }^{[6]}$

Semiology of seizures related to NCC is varied. Patients with multiple parasites may present with focal seizures and those with a single lesion develop generalized seizures. ${ }^{[7]}$ The lack of anatomic-semiologic correlation between cysticerci location and seizure semiology in a sizable proportion of patients with epilepsy and NCC has long been a cause of debate and concern. This has even led to the hypothesis that both epilepsy and NCC might simply occur by chance in areas where NCC is endemic. While this is theoretically possible, $\mathrm{MRI}$ findings of inflammatory changes surrounding calcified cysticerci after a seizure in about $50 \%$ of cases, provides strong evidence favoring a cause-andeffect relationship between NCC and seizures. ${ }^{[8]}$ In other cases, particularly in NCC patients with medically refractory epilepsy, chronic seizures have been shown to come from an associated atrophic or sclerotic hippocampus and not from the parasites themselves. ${ }^{\left[{ }^{[9]}\right.}$ In these cases, the damaged hippocampus is for sure not an innocent bystander, but the result of signals or forces -- epileptogenic or inflammatory -- coming from the parasites.
Most patients with hippocampal sclerosis and epilepsy -- particularly mesial temporal lobe epilepsy (MTLE) have history of perinatal trauma, recurrent febrile seizures, status epilepticus, or traumatic brain injury. Such initial precipitating injuries often lead to the development of neuronal loss in CA1 and CA3 hippocampal layers. ${ }^{[10]}$ The increasingly recognized association between granular or calcified lesions NCC lesions located within the hippocampus or in the adjacent cerebral tissue, points to this parasitic disease as the initial precipitating injury causing hippocampal atrophy and sclerosis. ${ }^{[11-13]}$ In addition, pathological reports have shown neuronal loss in the CA1 layer and gliosis, as well as the presence of a severe inflammatory reaction in the brain parenchyma surrounding calcified cysticerci. ${ }^{[14]}$ In this view, it has been postulated that calcified cysticerci could generate the development of both seizures and late hippocampal atrophy that will perpetuates the seizure disorder.

Hippocampal atrophy has also been documented in patients with calcified cysticerci located outside hippocampal areas. Different studies from Brazil and the Indian subcontinent, have revealed a significantly higher than expected prevalence of cysticercotic lesions among patients with MTLE undergoing surgery for medically intractable epilepsy. ${ }^{[11-15]}$ This, together with the finding that patients with NCC and MTLS/ hippocampal sclerosis have less often history of other types of initial precipitating injuries (febrile seizures) than those with MTLS/hippocampal sclerosis alone, led to the concept that a causal relationship between NCC and MTLE with hippocampal sclerosis exists. In addition, a population-based study conducted in an Ecuadorian rural population showed a strong association between NCC and HS in communitydwelling adults. ${ }^{[16]}$ In the same population, it was demonstrated that this association is strongly related to age, suggesting that NCC-related hippocampal atrophy takes a long time to develop. ${ }^{[17]}$ Interestingly, many of the studied individuals do not had epilepsy or electroencephalography evidence of paroxysmal abnormalities, showing that the association between NCC and hippocampal atrophy may occur irrespective of seizure activity (unpublished data).

In NCC patients, the relationship between epilepsy and hippocampal atrophy/sclerosis is most likely bidirectional. According to a current hypothesis, parasite-induced inflammation is the trigger for repetitive seizures, which may cause hippocampal atrophy, which is the pathological substrate for the subsequent development of MTLE. Parasites may be located outside the hippocampal region, suggesting 
a remote harmful effect of NCC-induced reactive seizures. It is also possible that cysticerci may lead to an inflammation-mediated hippocampal damage, not requiring recurrent seizures as a causative factor, as has been demonstrated in experimental studies. ${ }^{[18,19]}$

Longitudinal studies are required to demonstrate a causal relationship between NCC and hippocampal atrophy. If this causal relationship truly exists, specific biomarkers could be identified to examine mechanisms of hippocampal epileptogenesis in humans, which have been scarcely investigated. ${ }^{[20]}$ This knowledge might allow the development of interventions directed to prevent chronic epilepsy in NCC and other forms of acquired epilepsy.

\section{DECLARATIONS}

\section{Authors' contributions}

Study design and manuscript drafting: O.H. Del Brutto Literature review, significant contribution to intellectual manuscript content: V.J. Del Brutto

\section{Financial support and sponsorship}

This study was partially supported by Universidad Espíritu Santo, Guayaquil, Ecuador.

\section{Conflicts of interest}

There are no conflicts of interest.

\section{Patient consent \\ Not applicable.}

\section{Ethics approval Not applicable.}

\section{REFERENCES}

1. Lescano AG, Garcia HH, Gilman RH, Gavidia CM, Tsang VCW, Rodriguez S, Moulton LH, Villaran MV, Montano SM, Gonzalez AE; the Cysticercosis Working Group in Peru. Taenia solium cysticercosis hotspots surrounding tapeworm carriers: clustering on human seroprevalence but not on seizures. PLoS Negl Trop Dis 2009;3:e371.

2. Garcia HH, Nash TE, Del Brutto OH. Clinical symptoms, diagnosis, and treatment of neurocysticercosis. Lancet Neurol 2014;13:1202-15.

3. Bruno E, Bartoloni A, Zammarchi L, Strohmeyer M, Bartalesi F, Bustos JA, Santivañez S, García HH, Nicoletti A; COHEMI Project Study Group. Epilepsy and neurocysticercosis in Latin America: a systematic review and meta-analysis. PLoS Negl Trop Dis 2013; 7:e2480.

4. Del Brutto $\mathrm{OH}$, Garcia HH. Neurocysticercosis in nonendemic countries: time for a reappraisal. Neuroepidemiology 2012;39:145-6.

5. Kimura-Hayama ET, Higuera JA, Corona-Cedillo R, Chávez-Macías L, Perochena A, Quiroz-Rojas LY, Rodríguez-Carbajal J, Criales JL. Neurocysticercosis: radiologic-pathologic correlation. Radiographics
2010;30:1705-19.

6. Nash TE, Del Brutto OH, Butman JA, Corona T, Delgado-Escueta A, Duron RM, Evans CA, Gilman RH, Gonzalez AE, Loeb JA, Medina MT, Pietsch-Escueta S, Pretell EJ, Takayanagui OM, Theodore W, Tsang VC, Garcia HH. Calcific neurocysticercosis and epileptogenesis. Neurology 2004;62:1934-8

7. Singh G, Burneo JG, Sander JW. From seizures to epilepsy and its substrates: neurocysticercosis. Epilepsia 2013;54:783-92.

8. Nash T. Edema surrounding calcified intracranial cysticerci: clinical manifestations, natural history, and treatment. Pathog Glob Health 2012;106:275-9.

9. Bianchin MM, Velasco TR, Santos AC, Sakamoto AC. On the relationship between neurocysticercosis and mesial temporal lobe epilepsy associated with hippocampal sclerosis: coincidence or a pathogenic relationship. Pathog Glob Health 2012;106:280-5.

10. Thom M, Eriksson S, Martinian L, Caboclo LO, McEvoy AW, Duncan JS, Sisodiya SM. Temporal lobe sclerosis associated with hippocampal sclerosis in temporal lobe epilepsy: neuropathological features. J Neuropathol Exp Neurol 2009;68:928-38.

11. Bianchin MM, Velasco TR, Araffljo D Jr, Alexandre V Jr, Wichert-Ana L, Terra-Bustamante VC, Martins APP, Santos AC, Walz R, Assirati JA Jr, Carlotti CG Jr, Takayanagui OM, Sakamoto AC. Clinical and electrophysiological differences between mesial temporal lobe epilepsy and mesial temporal lobe epilepsy plus neurocysticercosis. Epilepsia 2006;47:244.

12. Velasco TR, Zanello PA, Dalmagro CL, Araújo D Jr, Santos AC, Bianchin MM, Alexandre V Jr, Walz R, Assirati JA, Carlotti CG Jr, Takayanagui OM, Sakamoto AC, Leite JP. Calcified cysticercotic lesions and intractable epilepsy: a cross sectional Study of 512 patients. J Neurol Neurosurg Psychiatry 2006;77:485-8.

13. Bianchin MM, Velasco TR, Wichert-Ana L, Alexandre V Jr, Araujo D Jr, dos Santos AC, Carlotti CG Jr, Takayanagui OM, Sakamoto AC. Characteristics of mesial temporal lobe epilepsy associated with hippocampal sclerosis plus neurocysticercosis. Epilepsy Res 2014;108:1889-95.

14. da Silva AV, Martins HH, Marques CM, Yacubian EM, Sakamoto AC, Carrete H Jr, da Silva Centeno R, Stavale JN, Cavalheiro EA. Neurocysticercosis and microscopic hippocampal dysplasia in a patient with refractory mesial temporal lobe epilepsy. Arq Neuropsiquiatr 2006;64:309-13.

15. Rathore C, Thomas B, Kesavadas C, Abraham M, Radhakrishnan K. Calcified neurocysticercosis lesions and antiepileptic drugresistant epilepsy: a surgically remediable syndrome? Epilepsia 2013;54:1815-22.

16. Del Brutto OH, Salgado P, Lama J, Del Brutto VJ, Campos X, Zambrano M, García HH. Calcified neurocysticercosis associates with hippocampal atrophy: a population-based study. Am J Trop Med Hyg 2015;92:64-8.

17. Del Brutto OH, Issa NP, Salgado P, Del Brutto VJ, Zambrano M, Lama J, García HH. The association between neurocysticercosis and hippocampal atrophy is related to age. Am J Trop Med Hyg 2017;96:243-8.

18. Del Brutto OH, Engel J Jr, Eliashiv DS, Salamon N, Garcia HH. Hippocampal sclerosis: the missing link of cysticercosis epileptogenesis? Epilepsia 2014;55:2077-8.

19. Del Brutto OH, Engel J Jr, Eliashiv DS, Garcia HH. Update on cysticercosis epileptogenesis: the role of the hippocampus. Curr Neurol Neurosci Rep 2016;16:1.

20. Pitkanen A, Engel J Jr. Past and present definitions of epileptogenesis and its biomarkers. Neurotherapeutics 2014;11:231-41. 